\title{
Evaluation of Microscopy, Culture and PCR Methods in the Laboratory Diagnosis of Genito-urinary Tuberculosis
}

\author{
Pranali Pingle ${ }^{1, *}$, Pradeep Apte ${ }^{2}$, Rakesh Trivedi ${ }^{3}$ \\ ${ }^{1}$ Microbiologist, Medicare Hospital and Research Centre, Indore \\ ${ }^{2}$ Biochemist and Lab incharge, Medicare Hospital and Research Centre, Indore \\ ${ }^{3}$ Principal, P.M.B.Gujarati Science College, Indore \\ *Corresponding author: pranalispingle@yahoo.com
}

Received December 09, 2013; Revised January 04, 2014; Accepted January 09, 2014

\begin{abstract}
Genitourinary tuberculosis (GUTB) is the second most common form of extrapulmonary tuberculosis, with more than $90 \%$ of cases occurring in developing countries. In GUTB, the kidneys are the most common sites of infection and are infected through hematogenous spread of the bacilli, which then spread through the renal and genital tract. Diagnosis of TB is often delayed owing to the nonspecific nature of its presentation; therefore, a high degree of suspicion should be exercised and a systematic approach should be taken during investigation. The aim of this study was to apply bleach concentration method for detection of AFB in 5-day morning urine samples obtained from the suspects of urinary tuberculosis and to correlate the results with conventional Zeihl Neelsen (ZN) staining, TB culture and TB-PCR. A total of 46 samples were studied from clinically suspected cases of urinary tuberculosis. All the samples were processed for conventional ZN staining, Bleach concentration followed by ZN staining, TB culture on LJ media and TB-PCR (IS 6110) by standard protocols. Out of the 46 samples evaluated all were negative (0\%) by conventional ZN staining, while the positivity increased to 7(15.22\%) by bleach concentration method, the gold standard i.e. TB culture had 9(19.56\%) positive and the TB-PCR gave 4(8.69\%) positive. The results revealed that bleach concentration method was superior to conventional ZN staining method and TB-PCR. Though TB culture was found to be the best method, but it takes a long time for the diagnosis.
\end{abstract}

Keywords: Genito-urinary tuberculosis, M.tuberculosis, conventional ZN staining, bleach method, PCR, TB culture

Cite This Article: Pranali Pingle, Pradeep Apte, and Rakesh Trivedi, "Evaluation of Microscopy, Culture and PCR Methods in the Laboratory Diagnosis of Genito-urinary Tuberculosis." American Journal of Infectious Diseases and Microbiology 2, no. 1 (2014): 17-21. doi: 10.12691/ajidm-2-1-4.

\section{Introduction}

Tuberculosis (TB) remains one of the leading infectious diseases throughout the world accounting for about 8.8 million cases in 2010 [1]. India alone accounted for 2.02.5 million cases in 2010, thus contributing approximately $26 \%$ of all TB cases worldwide [2]. According to National Tuberculosis Control Programmes (NTPs), 2.6 million new cases of sputum smear-positive pulmonary TB (PTB), 2.0 million new cases of sputum smear-negative PTB and 0.8 million new cases of extrapulmonary tuberculosis (EPTB) were observed in 2010 worldwide [3]. EPTB has become more common since the advent of human immunodeficiency virus (HIV) infection [3]. Various methods are employed for the diagnosis of EPTB such as smear microscopy, culture, histopathology, tuberculin skin test (TST), interferon-gamma release assays (IGRAs) and nucleic acid amplification (NAT) tests [4,5]. The usefulness, priority and scope of various techniques used in $\mathrm{TB}$ diagnosis depend on the epidemiological situation prevailing in individual countries and on the resources available. In most low income countries, the only practically available bacteriological method for diagnosing extrapulmonary tuberculosis is direct smear microscopy for AFB.Drawbacks of smear microscopy include low and variable sensitivity values $(0-40 \%)$ and cannot differentiate between Mycobacterium tuberculosis and non-tuberculous mycobacteria (NTM) [6,7,8].Culture identification for $M$. tuberculosis also has variable sensitivities (0-80\%) in different extrapulmonary specimens $[9,10,11,12]$ with turnaround time of $4-8$ weeks and requires skillful technicians [13].

The TST is useful for the diagnosis of EPTB, however, false-positive reactions occur due to previous Bacille Calmette-Guérin (BCG) vaccination or sensitization to NTM and false-negative results occur in the immunocompromised patients, elderly persons or overt forms of TB [5]. The in vitro T-cell based IGRAs have been used for the diagnosis of both latent and active TB but these assays do not differentiate between latent and active TB infection [14]. Therefore, these assays have no utility in disease diagnosis and treatment in highly 
endemic countries [15]. The analysis of cytokine profiles in $M$. tuberculosis-specific CD4+ $\mathrm{T}$ cells by polychromatic flow cytometry could differentiate between active and latent TB [16]. The use of flow cytometry as part of the diagnostic algorithm has been exploited for EPTB infection (e.g. pleural TB), however, due to high cost, its use as a rapid diagnostic test is limited in the resource-poor settings [17]. The serological antibody detection tests have been widely used and the tools of genomics and proteomics have led to the use of several antigens for the diagnosis of both PTB and EPTB patients [18]. Due to inconsistent and imprecise estimates, the World Health Organization (WHO) Expert Group Meeting convened in 2010 has strongly recommended against the use any of these serological tests for the diagnosis of both PTB and EPTB cases [19]. Newer molecular techniques, such as polymerase chain reaction (PCR), although rapid ; are too costly to be routinely used in the settings where most TB cases occur.[20] The reason for widely used IS6110 in PCR tests is the presence of its multiple copies in $M$. tuberculosis complex genome which is believed to confer higher sensitivity $[21,22,23]$. However, few studies from different geographical regions of the world have reported that some clinical isolates have either a single copy or no copy of IS6110 which leads to false negative results $[24,25]$. For avoiding the contamination during amplification and increasing the sensitivity, new approaches such as nested PCR (two step amplification) $[26,27]$ and multiplex PCR (amplification of two or more gene targets simultaneously) [28,29,30,31] have been exploited for EPTB diagnosis.

During PCR amplification, several inhibitors such as host proteins, blood and even eukaryotic DNA in extrapulmonary specimens are known to interfere with the sensitivity of PCR and give false negative results $[7,32,33]$. Due to extremely high sensitivity of PCR, the carryover contamination of amplicon, previous infection or asymptomatic EPTB infection at another site could result into false positivity [33,34]. The false positivity of PCR reports in absence of clinical findings poses serious challenges these days in diagnosing EPTB cases [25].

Various studies have shown bleach concentration method is cost effective, sensitive, versatile and safe procedure for demonstration of tubercle bacilli and is very valuable in diagnosing case of extra pulmonary tuberculosis $[35,36,37,38]$ and would benefit the patients to receive an early and specific treatment, although it is not confirmed by WHO experts[39].

We have used the bleach concentration method in urinary samples which is in its type the first study. Using 5 day morning urine samples as a source, the bleach concentration prior to Zeihl-Nelson (ZN) staining was evaluated to see the increase in positivity of AFB as compared to direct ZN staining. Further the results were also compared by culture on Lowenstein-Jensen (LJ) media and TB-PCR.

\section{Materials and Methods}

A study of 46 cases of suspected Genitourinary TB was done. This study was performed between $1^{\text {st }}$ January 2012-31 $1^{\text {st }}$ December 2012. This included cases of genitourinary TB. The samples included were 5 days morning urine sample which were collected from the patients attending various out -patient and in-patient departments at the Medicare hospital, Indore. The selection of cases on basis of "sterile pyuria" with WBC's present and with or without haematouria in urine but a negative routine bacterial culture(in renal TB). The cases included belonged to the age groups from 40 to 65 . There were 29 males (63.04\%) and 17 females (37.77\%). The details of the samples and the various test findings are indicated in the Table 1 . All the samples were processed for direct microscopy using conventional ZN staining, bleach concentration method, TB culture, and PCR.

\begin{tabular}{|} 
Table 1. Comparison of urine samples treated by direct ZN staining, bleach concentration method, AFB culture and PCR \\
\begin{tabular}{|c|c|c|c|c|c|c|}
\hline \multirow{2}{*}{ samples } & \multirow{2}{*}{ sex } & \multirow{2}{*}{ No of patients } & \multicolumn{5}{|c|}{ Findings (positive) } \\
\cline { 4 - 8 } & & & ZN & Bleach concentration & LJ culture & PCR \\
\hline \multirow{2}{*}{5 day morning urine samples } & male & 29 & 0 & 4 & 4 & 2 \\
\cline { 2 - 8 } & female & 17 & 0 & 3 & 5 & 2 \\
\hline Total & & 46 & 0 & 7 & 4 \\
\hline
\end{tabular}
\end{tabular}

Five early morning specimens were collected on consecutive days and the urine was allowed to settle at $4^{\circ} \mathrm{C}$. The resulting samples were pooled and centrifuged at $3000 \mathrm{~g}$ for $20 \mathrm{~min}$ and the final volume was adjusted to 3 to 6 $\mathrm{ml}$ depending on the pellet size. The sediment were divided into three equal portions and were then used for analysis.

The first portion was used for direct ZN staining and bleach concentration followed by ZN staining.

\subsection{ZN Staining}

ZN staining was performed by conventional method.

\subsection{Bleach Concentration Method}

It was performed using slight modification of the original method [40]. Sterile, disposable test tubes were used for bleaching. In this approximately $1 \mathrm{ml}$ of the centrifuged material of 5 days morning sample was mixed with $1 \mathrm{ml}$ of commercially available $4 \%$ sodium hypochlorite (merck). After thorough mixing the mixture was incubated for 15 minutes at room temperature with frequent mixing at intervals. (a prolonged exposure to bleach and a higher concentration of bleach solution reduces the possibility to detect AFB [41]. An equal volume of commercially available distill water was then added and mixed thoroughly using vortex mixer or disposable sterile plastic pipette and then centrifuged at $3000 \mathrm{~g}$ for 15 minutes. The supernatant was discarded, and smears were prepared using one drop of the sediment, air dried, heat fixed and stained by ZN staining technique. As a control $2 \mathrm{ml}$ of distilled water was centrifuged and the sediment was stained by ZN staining to rule out any error due to contamination while testing each specimen. After conventional $\mathrm{ZN}$ staining and bleach concentration methods the smears were examined under 100 oil fields for the presence of AFB which is the standard procedure. 


\subsection{LJ Culture}

The second portion was used for culture in which the deposits were decontaminated by adding an equal volume of molar sodium hydroxide and mixed for $30 \mathrm{~min}$. After centrifugation the sample were neutralized by $8 \% \mathrm{HCl}$ with the help of neutral red and then cultured on LJ slant.

\subsection{PCR}

The third portion was used for DNA extraction by Qiagen kit and followed by multiplex PCR for the IS6110 gene specific for M.tuberculosis.

\subsubsection{DNA Extraction}

Urine specimens were treated with NALC-NaOH method for the decontamination and liquefaction to obtain the pellet for DNA extraction.[24] The bacterial pellet was resuspended in 180 ul buffer ATL (supplied in QIAamp Tissue Kit, QIAGEN GmbH, Hilden, Germany). The extraction of TB DNA was performed according to QIAGEN kit protocol. The eluted DNA can be stored at20C until use in PCR.

\subsubsection{PCR Assay}

The Seeplex ${ }^{\mathrm{R}}$ MTB ACE detection uses multitarget (IS6110 and MPB64) and carries out both IS6110 and MPB64 PCR. The PCR mastermix was prepared according to standard protocol of the kit which contained primer pairs, DNA polymerase, buffer containing dNTPs, $\mathrm{MgCl}_{2}$ and stablizersand 8-MOP solution (which prevents carry over contamination). This $15 \mu \mathrm{l}$ of mastermix is mixed with $5 \mu \mathrm{l}$ of sample's nucleic acid. The PCR conditions for DNA amplification were an initial denaturation step of 94C for $15 \mathrm{~min}$, followed by 40 cycles of 94C for $0.5 \mathrm{~min}, 62 \mathrm{C}$ for $1.5 \mathrm{~min}, 72 \mathrm{C}$ for 1.5 min. and a final extension step at $72 \mathrm{C}$ for $10 \mathrm{~min}$. The PCR procedure was accomplished with a thermocycler TC 9600 (Perkin-Elmer Cetus). After detection step, irradiate UV light(365nm) onto PCR product for 20 min to prevent carry over contamination. Each experiment included positive and negative control tubes. The products of amplification were then analyzed by agarose gel electrophoresis.

\section{Results}

Out of the sample processed, AFB smears by conventional $\mathrm{ZN}$ staining were negative for all the samples (0\%) [Table 1].

Table 2. Distribution of patients according to Bleach concentration method

\begin{tabular}{|c|c|c|c|}
\hline Findings (positive) & $\begin{array}{c}\text { Total } \\
\text { samples }\end{array}$ & $\begin{array}{c}\text { Number of } \\
\text { patients }\end{array}$ & Percentage \\
\hline Only Bleach concentration & 46 & 0 & $0.00 \%$ \\
\hline Bleach + AFB smear & 46 & 0 & $0.00 \%$ \\
\hline Bleach + LJ Culture & 46 & 7 & $15.21 \%$ \\
\hline Bleach + PCR & 46 & 3 & $6.52 \%$ \\
\hline Total Bleach positive & 46 & 7 & $15.21 \%$ \\
\hline
\end{tabular}

Now when the samples were processed for bleach and then stained by ZN it detected AFB in 7 samples (15.21\%). Among the 7 bleach positive samples all were positive on
AFB culture, three were positive by PCR but all were negative by conventional ZN staining [Table 2].

Except the 7 samples which were positive by bleach method, there were two other samples $(n=9)(19.56 \%)$ which were detected by AFB culture which is considered to be a gold standard in TB diagnosis, while both the AFB culture positive samples were negative by PCR [Table 3].

Table 3. Distribution of patients according to $\mathrm{LJ}$ culture

\begin{tabular}{|c|c|c|c|}
\hline Findings (positive) & $\begin{array}{c}\text { Total } \\
\text { samples }\end{array}$ & $\begin{array}{c}\text { Number of } \\
\text { patients }\end{array}$ & Percentage \\
\hline OnlyLJ culture & 46 & 2 & $4.34 \%$ \\
\hline LJ culture + AFB smear & 46 & 0 & $0.00 \%$ \\
\hline LJ culture + Bleach conc & 46 & 7 & $15.21 \%$ \\
\hline LJ culture + PCR & 46 & 3 & $6.52 \%$ \\
\hline Total LJ culture & 46 & 9 & $19.53 \%$ \\
\hline
\end{tabular}

By PCR there were only four samples (8.69\%) positive for AFB, from which three samples were positive by all the methods except conventional $\mathrm{ZN}$ staining and there was only one sample which was positive by PCR and all other methods were negative [Table 4].

Table 4. Distribution of patients according to PCR

\begin{tabular}{|c|c|c|c|}
\hline Findings (positive) & $\begin{array}{c}\text { Total } \\
\text { samples }\end{array}$ & $\begin{array}{c}\text { Number of } \\
\text { patients }\end{array}$ & Percentage \\
\hline Only PCR & 46 & 1 & $2.17 \%$ \\
\hline PCR + AFB smear & 46 & 0 & $0.00 \%$ \\
\hline PCR + Bleach conc & 46 & 3 & $6.52 \%$ \\
\hline PCR + LJ culture & 46 & 3 & $6.52 \%$ \\
\hline Total PCR & 46 & 4 & $8.69 \%$ \\
\hline
\end{tabular}

Out of 46 samples 10 were reported as positive for TB while rest as negative.

When results of bleach concentration were compared to AFB culture by $\mathrm{Z}$ test the $\mathrm{P}$ value is $>0.05$ which in turn shows a close resemblance in between them.

\section{Discussion}

Genitourinary tuberculosis is one of the most common manifestations of extrapulmonary tuberculosis and represents $15 \%$ of all extrapulmonary tuberculosis cases [42]. Renal TB occurs up to 20 times more frequently in kidney transplant recipients than in the general population. The early diagnosis of renal TB is very important in preventing progressive destruction of the kidney [43].

In the present study all the samples were negative for Acid fast bacilli by ZN staining which was contradicting the study of Warren D et.al, where they found Acid-fast staining as the most reliable test, with a sensitivity of $22 \%$ to $81 \%$ [44]. A study by A.Webster and D J Wright showed only $0.2 \%$ positive results on $\mathrm{ZN}$ staining.[45].Khaled $G$ et al reported genitourinary TB from the samples obtained from 300 symptomatic patients in $0.66 \%$ on $\mathrm{ZN}$ staining [46]. However, the results of our study were just contradicting the study of Fazal-urRehman et al where they had AFB in 13 patients i.e. sensitivity of $51.5 \%$ from 50 symptomatic patients of genitourinary TB [47].

A study by Mete $C$ et al showed that detection of acidfast bacilli from urine samples by microscopy (ZiehlNeelsen acid fast stain) is not reliable, because of the possible presence of $\mathrm{M}$. smegmatis, which may be present 
as Commensals and that decolourization with acid-alcohol should be used [48].

Our study revealed low positivity by LJ culture (19.53\%) when compared to studies by Hemal A K et al (30.95\%), SS Negi (48.9\%) [49,50]. Gracia R. et al stated that, the rate of positive results on culture can be as low as $10.7 \%$ or as high as $80 \%$, depending on the disease severity and how the disease is defined [51]. Khaled $G$ et al diagnosed a very less i.e. $0.66 \%$ patients on LJ culture [46].

PCR positive patients in our study were $8.69 \%$ which is very less as compared to the study by Negi $S$ et al (74.4\%), Hemal A K et al (80.95\%), and Bhanu et al. (53.3\%) [49,50,52].

The study by Leonardo A. Sechi et al (6.3\%) showed low positivity as compared with the present study[53].

The patients showing positive results on bleach concentration method, TB culture and PCR were treated with anti- tubercular drugs (ATT).

In the present study TB culture method followed by Bleach concentration microscopy diagnosed the majority cases of GUTB tuberculosis even when other diagnostic modalities were negative demonstrating these as useful techniques in the diagnosis of extra pulmonary tuberculosis.

The limitation of this study was that BACTEC TB culture were not performed.

\section{Conclusion}

Genitourinary tuberculosis is not very common but it is considered as a frequent presentation of extra-pulmonary tuberculosis. On basis of the increased positivity observed by the bleach concentration prior to $\mathrm{ZN}$ staining it can be recommended as an initial step in the diagnosis of renal TB rather than conventional ZN staining. Conventional methods of diagnosing renal TB i.e. HPE and LJ culture also have a place, especially in government set ups where BACTEC and PCR are not done routinely due to lack of resources. Though culture remains the gold standard for the diagnosis of TB, Bleach concentration method should also be collaborated with PCR, culture or histopathology before starting the treatment. A large case- control studies are required to suggest the most appropriate and cost effective test for the diagnosis of Renal TB.

\section{References}

[1] Griffiths G, Nystrom B, Sable SB, Khuller GK. Nanobead-based interventions for the treatment and prevention of Tuberculosis. Nat Rev Microbiol 2010; 8: 827-34.

[2] WHO. The sixteenth global report on Tuberculosis:2011.

[3] World Health Organization Global tuberculosis control. WHO report, 2011.

[4] Katoch VM. Newer diagnostic techniques for tuberculosis. Indian J Med Res2004; 120: 418-428.

[5] Lange C \& Mori T Advances in the diagnosis of tuberculosis. Respirology 2010; 15: 220-240.

[6] Liu KT, Su WJ \& Perng RP Clinical utility of polymerase chain reaction for diagnosis of smear-negative pleural tuberculosis. J Chin Med Assoc 2007; 70:148-51.

[7] Haldar S, Sharma N, Gupta VK \& Tyagi JS Efficient diagnosis of tuberculous meningitis by detection of Mycobacterium tuberculosis DNA in cerebrospinal fluid filtrates using PCR. J Med Microbiol 2009; 58: 616-24
[8] Derese Y, Hailu E, Assefa T, Bekele Y, Mihret A, Aseffa A, Hussien J, Ali I \& Abebe M Comparison of PCR with standard culture of fine needle aspiration samples in the diagnosis of tuberculosis lymphadenitis. J Infect Dev Ctries 2012; 6: 53-7.

[9] Padmavathy L, Rao L \& Veliath A, Utility of polymerase chain reaction as a diagnostic tool in cutaneous tuberculosis. Indian $\mathrm{J}$ Dermatol Venereol Leprol 2003; 69: 214-16.

[10] Sharma SK \& Mohan A Extrapulmonary tuberculosis. Indian J Med Res 2004; 120: 316-353.

[11] Takahashi T, Tamura M, Asami $\mathrm{Y}$ et al. Novel wide-range quantitative nested real-time PCR assay for Mycobacterium tuberculosis DNA: clinical application for diagnosis of tuberculous meningitis. J Clin Microbiol 2008; 46: 1698-1707.

[12] Abbara A \& Davidson RN Etiology and management of genitourinary tuberculosis. Nat Rev Urol 2011; 8: 678-88.

[13] Mehta PK, Kalra M, Khuller GK, Behera D \& Verma I, Development of an ultrasensitive polymerase chain reactionamplified immunoassay (Immuno-PCR) based on mycobacterial RD antigens: implications for the serodiagnosis of tuberculosis. Diag Microbiol Infect Dis 2012; 72: 166-74.

[14] Pai M \& O’Brien R New diagnostics for latent and active tuberculosis: state of the art and future prospects. Semin Respir Crit Care Med 2008; 29: 560-8.

[15] Dyrhol-Riise AM, Gran G, Wentzel-Larsen T, Blomberg B, Haanshuus CG \& Mørkve O, Diagnosis and follow-up of treatment of latent tuberculosis; the utility of the QuantiFERONTB Gold In-tube assay in outpatients from a tuberculosis lowendemic country. BMC Infect Dis 2010; 10: 57.

[16] Harari A, Rozot V, Enders FB et al. Dominant TNF- $\alpha+$ Mycobacterium tuberculosis-specific CD4 $+\mathrm{T}$ cell responses discriminate between latent infection and active disease. Nat Med. 2011; 17: 372-6.

[17] Sutherland JS, Garba D, Fombah AE, Mendy-Gomez A, Mendy FS, Antonio M, Townend J, Ideh RC, Corrah T \& Ota MO Highly accurate diagnosis of pleural tuberculosis by immunological analysis of the pleural effusion. PLoS One 2012; 7: e30324.

[18] Steingart KR, Flores LL, Dendukuri N, Schiller I, Laal S, Ramsay A, Hopewell PC \& Pai M Commercial serological tests for the diagnosis of active pulmonary and extrapulmonary tuberculosis: an updated systematic review and meta-analysis. PloS Med 2011;8: e1001062.

[19] Morris K, WHO recommends against inaccurate tuberculosis tests. Lancet 2011; 377: 113-114.

[20] Angeby KA, Hoffners SE, Diwan VK. Should the 'bleach microscopy method' be recommended for improved case detection of tuberculosis? Literature review and key person analysis. Int J Tuber Lung Dis 2004;8: 806-15.

[21] Lima DM, Colares JK, \& da Fonseca BA Combined use of the polymerase chain reaction and detection of adenosine deaminase activity on pleural fluid improves the rate of diagnosis of pleural tuberculosis. Chest. 2003; 124:909-14.

[22] Rafi W, Venkataswamy MM, Ravi V \& Chandramuki A, Rapid diagnosis of tuberculous meningitis: a comparative evaluation of in-house PCR assays involving three mycobacterial DNA sequences, IS6110, MPB-64 and $65 \mathrm{kDa}$ antigen. J Neurol Sci 2007;252: 163-8.

[23] Jin XJ, Kim JM, Kim HK et al. Histopathology and TB-PCR kit analysis in differentiating the diagnosis of intestinal tuberculosis and Crohn's disease. World J Gastroenterol 2010;16: 2496-2503.

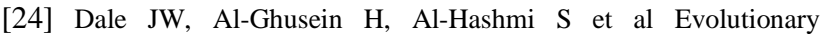
relationships among strains of Mycobacterium tuberculosis with few copies of IS6110. J Bacteriol 2003;185: 2555-62.

[25] Thangappah RB, Paramasivan CN \& Narayanan S, Evaluating PCR, culture \& histopathology in the diagnosis of female genital tuberculosis. Indian J Med Res 2011; 134: 40-46.

[26] Torrea G, Van de Perre P, Ouedraogo $M$ et al. PCR-based detection of the Mycobacterium tuberculosis complex in urine of HIV-infected and uninfected pulmonary and extrapulmonary tuberculosis patients in Burkina Faso. J Med Microbiol 2005;54: 39-44.

[27] Agashe V, Shenai S, Mohrir G, Deshmukh M, Bhaduri A, Deshpande R, Mehta A \& Rodrigues C Osteoarticular tuberculosis-diagnostic solutions in a disease endemic region. J Infect Dev Ctries 2009; 3: 511-16.

[28] Okazaki T, Ebihara S, Takahashi H, Asada M, Sato A, Seki M, Ohto H \& Sasaki H, Multiplex PCR-identified cutaneous tuberculosis evoked by Mycobacterium bovis BCG vaccination in a healthy baby. J Clin Microbiol 2005; 43: 523-5. 
[29] Colmenero JD, Morata P, Ruiz-Mesa JD, Bautista D, Bermudez P, Bravo MJ \& Queipo-Ortuño MI Multiplex real-time polymerase chain reaction: a practical approach for rapid diagnosis of tuberculous and brucellar vertebral osteomyelitis. Spine 2010; 35: E1392-6.

[30] Sharma K, Sharma A, Ray P, Sharma SK, Modi M, Prabhakar S,Varma S \& Sharma M, Multiplex PCR for rapid diagnosis of tuberculous meningitis. J Neurol 2011a; 258: 1781-1787.

[31] Sharma K, Sharma A, Sharma SK, Sen RK, Dhillon MS \& Sharma M, Does multiplex Polymerase Chain Reaction increase the diagnostic percentage in osteoarticular tuberculosis? A prospective evaluation of 80 cases. Int Orthop 2011b; 36: 255-259.

[32] Gan HT, Chen YQ, Ouyang Q, Bu H \& Yang XY, Differentiation between intestinal tuberculosis and Crohn's disease in endoscopic biopsy specimens by polymerase chain reaction. Am J Gastroenterol 2002; 97: 1446-1451.

[33] Sun YS, Lou SQ, Wen JM, Lv WX, Jiao CG, Yang SM \& Xu HB, Clinical value of polymerase chain reaction in the diagnosis of joint tuberculosis by detecting the DNA of Mycobacterium tuberculosis. Orthop Surg 2011; 3: 64-71.

[34] Honore-Bouakline S, Vincensini JP, Giacuzzo V, Lagrange PH \& Herrmann JL, Rapid diagnosis of extrapulmonary tuberculosis by PCR: impact of sample preparation and DNA extraction. J. Clin. Microbio. 2003; 41: 2323-29.

[35] Khubnani H, Munjal K. Application of bleach method in diagnosis of extra-pulmonary tuberculosis.Indian J Pathol Microbiol. 2005; 48: $546-50$

[36] Gangane N, Anshu, Singh R. Role of modified bleach method in staining of acid-fast bacilli in lymph node aspirates. Acta Cytol. 2008; 52: 325-8.

[37] Annam V, Karigoudar MH, Yelikar BR India Improved microscopical detection of acid-fast bacilli by the modified bleach method in lymphnode aspirate Indian J Pathol Microbiol. 2009; 52:349-52.

[38] Chandrasekhar B, Prayaga AK. Utility of concentration method by modified bleach technique for the demonstration of acid-fast bacilli in the diagnosis of tuberculous lymphadenopathy. J Cytol. 2012; 29:165-8.

[39] A. Cattamanchi, J. L. Davis, M. Pai, L. Huang, P. C. Hopewell, and K. R. Steingart Does Bleach Processing Increase the Accuracy of Sputum Smear Microscopy for Diagnosing Pulmonary Tuberculosis? J. Clin. Microbiol. 2010; 48: 2433-243.

[40] Aber VR, Allen BW, Mitchinson DA, Ayuma P, Edwards EA, Keyes AB. Quality control in Tuberculosis bacteriology. Laboratory studies on isolated positive cultures and the Efficiency of direct smear examination. Tubercle.1980; 61: 123-33.

[41] Yassin M, Cuveas AEL, Gebrexabher H, Squire SB. Efficacy and safety of short - term Bleach digestion of sputum in case finding for Pulmonary Tuberculosis in Ethiopia. Int. J. Tuberc Lung Dis. 2003; 7:678-83.

[42] Raviglione MC, O’Brien RJ. Tuberculosis. In: Fauci AS, Braunwald E, Kasper DL, eds. Harrison's principles of internal medicine Vol 1. 17th ed. New York: McGraw-Hill; 2008: 1006-20.

[43] Wise GJ Urinary tuberculosis: modern issues. Curr Urol Rep 2009; 10: 313-318.

[44] Warren D, Johnson JR, JohnsonCW, Franklin C. Lowe: Genitourinary Tuberculosis Campbell's Urology. 8th ed. Saunders; 2002.

[45] Webster A. and Wright D J Ziehl-Neelsen staining of urine deposits in the diagnosis of genitourinary tuberculosis. J Clin Pathol. 1985; 38: 236.

[46] Khaled Ghaleb,Magdy Afifi, and Mohamad El-Gohary Assessment of Diagnostic Techniques of Urinary Tuberculosis Mediterr J Hematol Infect Dis. 2013; 5:1.

[47] FAZAL-UR-REHMAN KHAN, FARHAN ARSHAD CHEEMA, MOHAMMAD USMAN KHAN Accuracy of Urinary PCR as Compared with Urine Culture for Early Diagnosis of Genitourinary Tuberculosis 2013.

[48] Mete C, ek*, Severin Lenk, Kurt G. Naber, Michael C. Bishop, Truls E. Bjerklund Johansen, Henry Botto, Magnus Grabe, Bernard Lobel, Juan Palou Redorta, Peter Tenke: EAUGuidelines for the Management of Genitourinary Tuberculosis European Urology 2005;48 : 353-362

[49] A K Hemal, N P Gupta, T P Rajeev, R Kumar, L Dar, P Seth Polymerase chain reaction in clinically suspected genitourinary tuberculosis: comparison with intravenous urography, bladder biopsy, and urine acid fast bacilli culture Urology (Impact Factor: 2.42) 2000; 56:570-4

[50] Negi SS, Khan SF, Gupta S, Pasha ST, Khare S, Lal S. Comparison of the conventional diagnostic modalities, bactec culture and polymerase chain reaction test for diagnosis of tuberculosis. Indian J Med Microbiol. 2005; 23:29-33.

[51] Garcia-Rodrigues, J. A. et al. Genitourinary Tuberculosis in Spain: review of 81 Cases. Clin. Infect. Dis. 1994; 18:557-561.

[52] Bhanu NV, Singh UB, Chakrabotty M, Suresh N, Arora J, Rana T et al. Improved diagnostic value of PCR in the diagnosis of female genital tuberculosis leading to infertility. J Med Microbiol 2005; 54:927-31.

[53] Leonardo A. Sechi, Maria Piera Pinna, Alberto Sanna, Piero Pirina, Franco Ginesu, Franca Saba, Antonio Aceti, Franco Turrini, Stefania Zanetti, Giovanni Fadda. Detection of Mycobacterium tuberculosis by PCR analysis of urine and other clinical samples from AIDS and non-HIV-infected patients Molecular and Cellular Probes 1997;11: 281-285. 